\title{
Measurements of Flammable Gas Concentration in Landfill Areas with a Low-Cost Sensor
}

\author{
Ignas Daugela ${ }^{1,2, * \mathbb{D}}$, Jurate Suziedelyte Visockiene ${ }^{1} \mathbb{D}$, Jurate Kumpiene ${ }^{3}$ and Ivan Suzdalev ${ }^{2}$ \\ 1 Department of Geodesy and Cadaster, Vilnius Gediminas Technical University, 10223 Vilnius, Lithuania; \\ juratesuziedelyte-visockiene@vilniustech.lt \\ 2 Antanas Gustaitis' Aviation Institute, Vilnius Gediminas Technical University, 10223 Vilnius, Lithuania; \\ ivan.suzdalev@vilniustech.lt \\ 3 Department of Civil, Environmental and Natural Resources Engineering, Luleå University of Technology, \\ 97187 Luleå, Sweden; Jurate.Kumpiene@ltu.se \\ * Correspondence: ignas.daugela@vilniustech.lt; Tel.: +37-0676-094-70
}

Citation: Daugela, I.; Suziedelyte Visockiene, J.; Kumpiene, J.; Suzdalev, I. Measurements of Flammable Gas Concentration in Landfill Areas with a Low-Cost Sensor. Energies 2021, 14, 3967. https://doi.org/10.3390/ en14133967

Academic Editors: Krzysztof Górecki and Rao Martand Singh

Received: 13 May 2021

Accepted: 29 June 2021

Published: 1 July 2021

Publisher's Note: MDPI stays neutral with regard to jurisdictional claims in published maps and institutional affiliations.

Copyright: (c) 2021 by the authors. Licensee MDPI, Basel, Switzerland. This article is an open access article distributed under the terms and conditions of the Creative Commons Attribution (CC BY) license (https:// creativecommons.org/licenses/by/ $4.0 /)$.

\begin{abstract}
Global warming, as the result of the negative impact of humans on climate change, has been observed based on various data sources. Various measures have aimed to reduce anthropogenic factors, and also to lower carbon dioxide $\left(\mathrm{CO}_{2}\right)$ and methane $\mathrm{CH}_{4}$ emissions. One of the main contributors to anthropogenic factors is organic waste in municipal solid waste landfills. There are many landfills where cost-effective rapid technologies for the identification and quantification of $\mathrm{CH}_{4}$ emission sites are not applied. There is still a need for the development of accessible and cost-effective methods that react in a real-time manner for the rapid detection and monitoring of methane emissions. This paper's main goal is to create a prototype sensor suitable for operational measurement of the gas value, suitable for integration into geodetic equipment or an unmanned aerial vehicle system. A sensor system (device) was developed, which consisted of three semiconductor sensors-MQ2, MQ4, and MQ135-which aimed to capture flammable gases $\left(\mathrm{CO}_{2}, \mathrm{CH}_{4}, \mathrm{O}_{2}\right.$ purity) and to evaluate the averages of the measured values from the components mounted on the board-the semiconductor sensors. The sensors were calibrated in a laboratory and tested in a closed landfill. The measurement data consisted of the read resistances (analog signal) from the MQ2, MQ4, and MQ135 sensors, and the relative humidity and the temperature (digital signal) of the DHT2 sensor with a timestamp calculated by the RTC module. The use of the method was confirmed because the sensors reacted as expected when placed in the vicinity of the gas collection well. Furthermore, the sensor will be tested and improved for field work in landfill sites.
\end{abstract}

Keywords: greenhouse gases; methane; regression analysis; sensor calibration; Arduino

\section{Introduction}

Greenhouse gas (GHG) emissions are one of the main drivers of climate change [1,2]. It is therefore important to monitor and forecast the release of $\mathrm{GHG}$, such as carbon dioxide $\left(\mathrm{CO}_{2}\right)$, nitrogen dioxide $\left(\mathrm{NO}_{2}\right)$ and methane $\left(\mathrm{CH}_{4}\right)$ into the environment. Municipal solid waste (MSW) landfills are among the important contributors of $\mathrm{CH}_{4}$ and $\mathrm{CO}_{2}$ to the atmosphere. Effective and cost-efficient detection technologies of the uncontrolled GHG emissions to the environment are needed.

At present, gas monitoring at MSW landfills in Lithuania is carried out in points defined in a monitoring plan. Emissions of $\mathrm{CH}_{4}, \mathrm{CO}_{2}$, hydrogen sulphide $\left(\mathrm{H}_{2} \mathrm{~S}\right)$ and oxygen $\left(\mathrm{O}_{2}\right)$, alongside air temperature and atmospheric (barometric) pressure are measured. At the points where the gas emissions from the landfill surface are detected, the gas flow density and emission flow are calculated. Atmospheric emissions $\left(\mathrm{CO}_{2}, \mathrm{CH}_{4}\right.$ and $\left.\mathrm{N}_{2} \mathrm{O}\right)$ can be determined with a Dräger multi-channel analyser X-am 7000 [3]. This sensor complies with the European Union Directive 94/9/EC for biogas meters. Measurements are performed in a $6877 \mathrm{~cm}^{3}$ stainless steel flow box [4-7]. Based on the performed gas 
concentration measurements in the "flow box" and the calculation results, a graph of the gas concentration change over time is plotted and a repeated monitoring report is prepared. A disadvantage of a closed gas flow measuring box is that the measurements are performed occasionally, e.g., several times a year to estimate seasonal or annual gas flow [5]. By this, uncontrolled emissions occurring in between the measurements are missed.

Methods providing more continuous measurements of changes in gas emissions and their composition might reduce the uncertainties. One such way is using remote sensing, where environmental information is obtained using open-platform electronic sensors and lasers integrated with cameras [8-11]. Various sensors capture the range of wavelengths and frequencies of electromagnetic radiation. The common sensor types are Red-GreenBlue (RGB), which is the most common colour model of visible light, and spectral, which can be single-spectrum or multispectral [12], and in recent years-hyper-spectral. This last type of camera has been used in research laboratories, artificial Earth satellites, airplanes, and in recent years, in unmanned aerial vehicles (UAV) to study the composition of the Earth's surface (including its chemistry) [11,12]. NASA (USA) has constructed the HyTES spectrometer for Earth science research, which can be used to detect individual spatial structures of plumes arising from $\mathrm{CH}_{4}, \mathrm{H}_{2} \mathrm{~S}, \mathrm{NH}_{3}, \mathrm{NO}_{2}$, and $\mathrm{SO}_{2}$ pollution sources [13-15]. Nevertheless, access to such techniques for a landfill operator is limited.

The abundance of sensors currently in production allows the development of opensource electronic systems suitable for air pollution monitoring, including meteorological indicators, such as temperature, wind speed, relative humidity, and pressure, and chemical indicators, such as $\mathrm{SO}_{2}, \mathrm{NO}, \mathrm{NO}_{2}, \mathrm{PM} 10, \mathrm{PM} 2.5, \mathrm{O}_{3}, \mathrm{CO}$, and volatile organic compounds (VOCs) [16]. Open-source systems can be used by a UAV due to their low cost, relatively small size and weight. A general spatial trend of concentrations and an accuracy of $\pm 30 \%$ could be acceptable for the detection and localisation of gas emission sources and for the additional monitoring of weak spots. Further investigations would require an accuracy of $<20 \%[16,17]$. To detect traces of GHG and VOCs in the lower atmosphere, a UAV can be fitted with various types of sensors and data results, supplemented by high-resolution processed RGB camera images, incorporated into Earth spatial GIS database systems for storage and further analysis [17]. Such solutions can be more accessible to landfill operators and provide data of acceptable quality for the fast identification of landfill gas leaks.

The aim of this study was to manufacture a prototype microcontroller based on a gas sensor array specialised for landfill area roving in points of interest that are selected from satellite and UAV images or in situ measurements. This prototype microcontroller can be a simple and cost-efficient alternative to the flow box method, affordable to any landfill operator.

\section{Materials and Methods}

\subsection{Study Area}

Testing was performed at the Kariotiskes landfill, located in Lithuania, Europe. This was the main municipal solid waste landfill for the capital city, Vilnius. The landfill was closed in 2008 and planted with vegetation a year later. Over two decades, the landfill has accumulated 3 million tons of waste. An observation deck has been built on the very top of the heap, and a thermal power plant has been opened at the Kariotiskes landfill, which produces energy from the landfill gas extracted here. However, whole territory must be observed for at least three decades.

The study was designed to check certain locations described by other remote sensing methods or find the weakest spot of the final landfill cover by moving in a site towards increasing readings in real-time. For better absolute accuracy or better precision, voltage readings, temperature, humidity, and flow regulation needed to be taken into account, as these are sources of errors in the field. After the localisation of certain problematic areas in landfills, at the moment, other methods should be used with better concentration accuracy; however, this prototype could solve the problem of finding hot spots influenced by $\mathrm{CH}_{4}$ emission quickly and cheaply for every landfill, as a complementary method to 
remote sensing. This is because other methods are expensive, require long or complex preparation and application, or results come after a couple of weeks because of logistics and laboratory work.

\subsection{Methods}

As this type of application of sensors in the device for landfills is novel, first of all, the principle and design of the prototype is provided. Then, a section on device calibration follows, and lastly, a section on measurement processes in the area of interest.

\subsubsection{Concept and System Design}

A new specialised sensor array was designed to measure the average concentration values of flammable gases (specific goal $-\mathrm{CH}_{4}$ ) from the components mounted on the board-semiconductor sensors. Semiconductor sensors respond to the ratio of the gas mixture to oxygen $\left(\mathrm{O}_{2}\right)$. Electronic humidity and vapour sensors, which measure the concentration of a liquid while it is in a gas phase, also work on this principle. The selected components used in household and industrial equipment (heating, ventilation, air conditioning, medical, meteorological equipment, warehousing, archive maintenance processes) are of high quality and have been improved according to user feedback because of a high demand lasting a couple of decades (Figure 1).
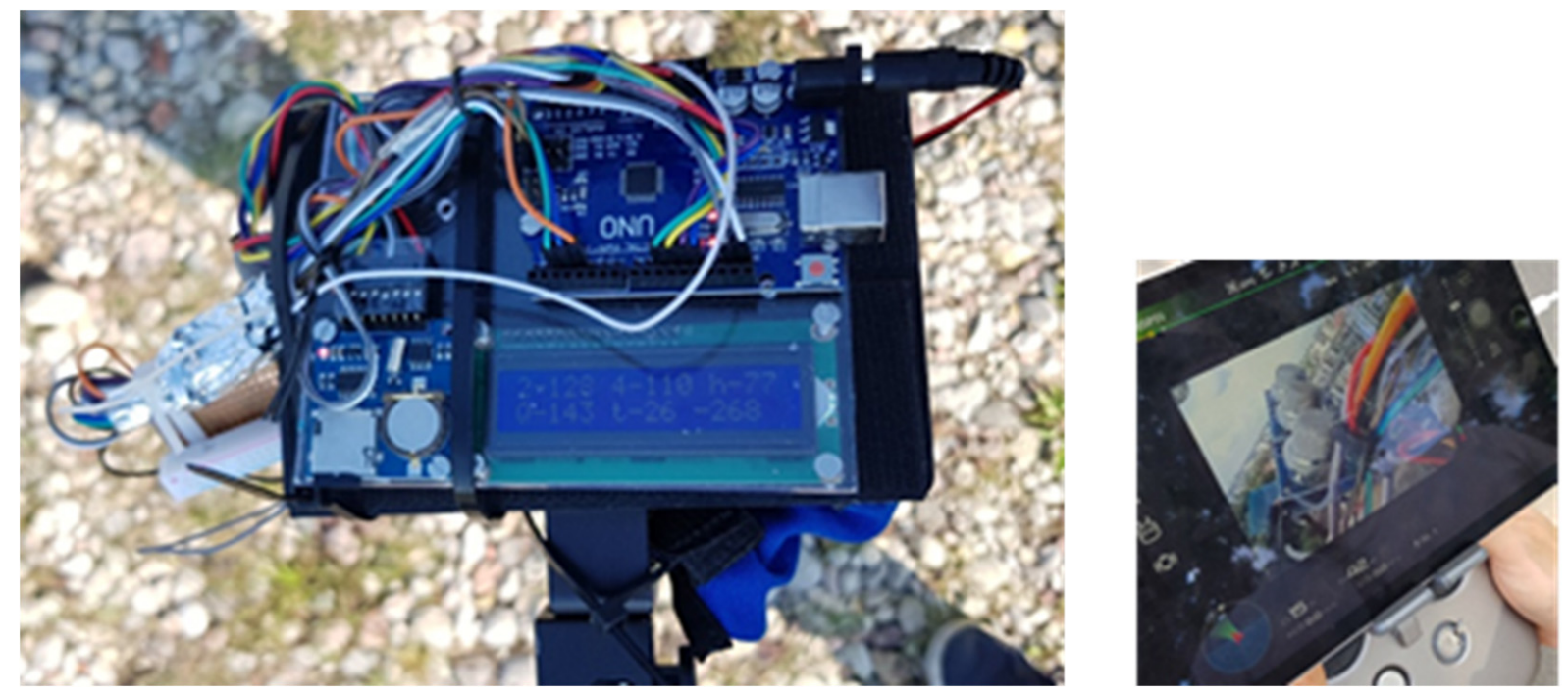

Figure 1. A device for measuring gas concentration in a landfill site.

The main components of new sensor system are illustrated in Figure 2. The system consists of three modules: (1) gas sensors array (MQ2, MQ4, MQ135, DHT22); (2) system controller; and (3) measurement-data capture.

The main sensor system module component MQ4 sensor is specialised in capturing flammable gases in the environment and has an increased sensitivity to $\mathrm{CH}_{4}$ gas (compared to other explosive gases). An additional component integrated to the module is the MQ2 explosive gas sensor, which is a semiconductor sensor optimised for a faster response and sensitivity to lower gas concentrations. The MQ135 sensor is sensitive to various air pollutants and changes in the ratio of carbon dioxide $\left(\mathrm{CO}_{2}\right)$ with other gases in the air. DHT22 registers current temperature and relative humidity.

The sensor system is controlled by an Arduino microcontroller, a two-line liquid crystal display (LCD) connected to its data output, an integrated module with a real-time clock (RTC) chip, and a secure digital (SD) card reader for date and time stamps recording (Figure 3). 


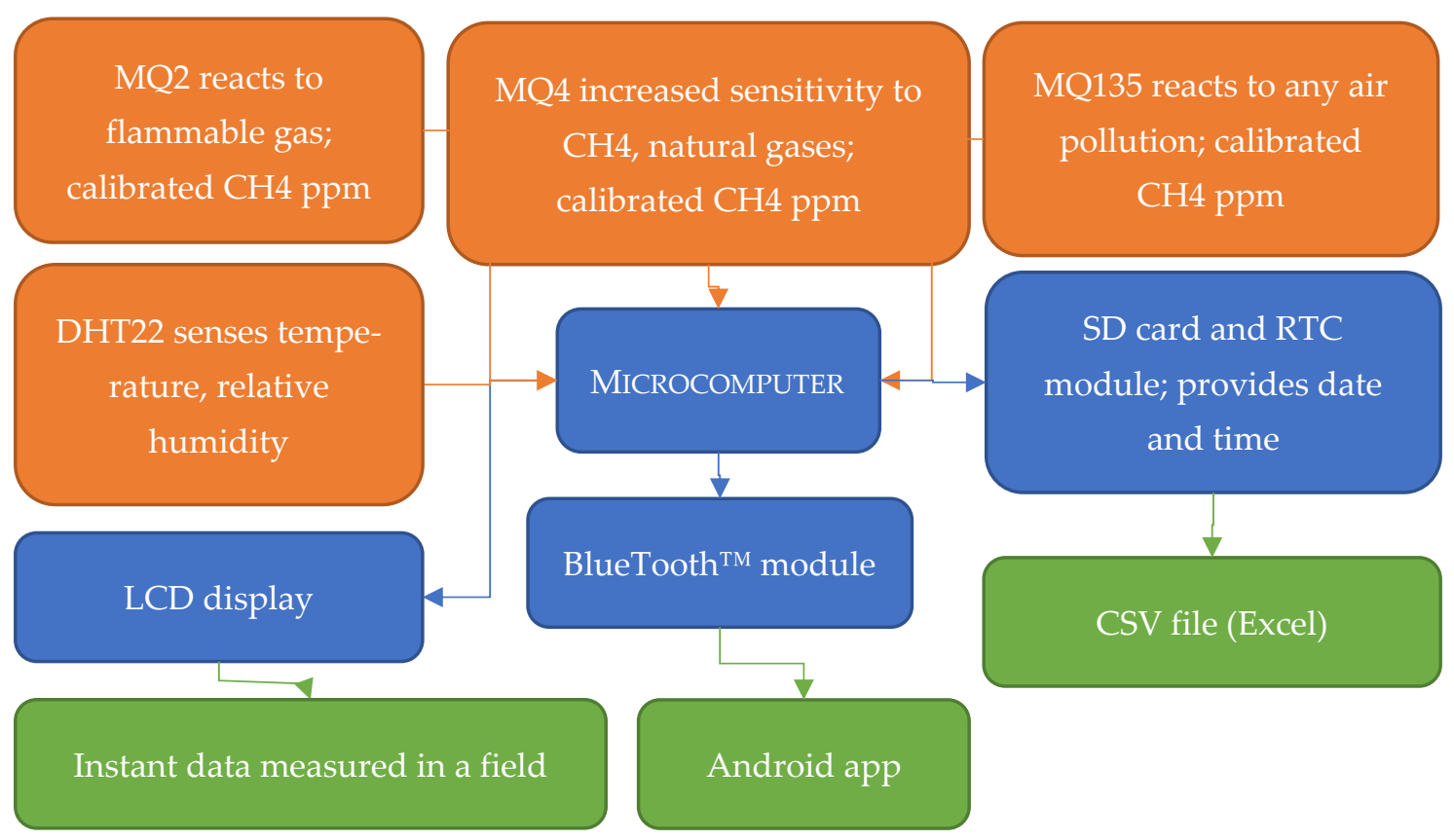

Figure 2. Schematics of interactions between the main components of the gas sensor system: gas sensors (orange), hardware for processing and output (blue), real time and saved results (green).

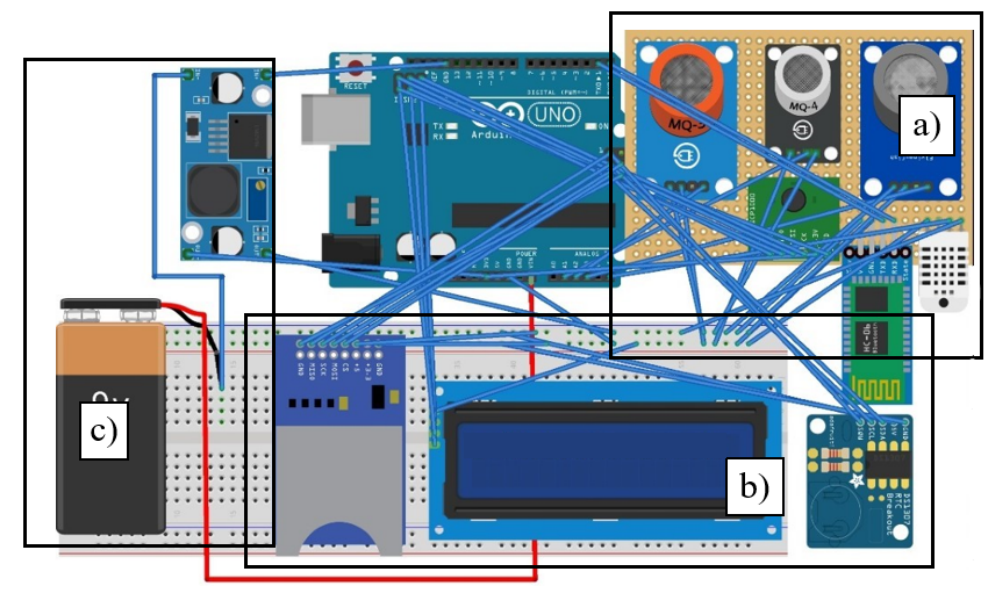

Figure 3. Arduino microcontroller with main block (approximate layout) (a) gas sensors (MQ2, MQ4 and MQ135) and temperature, humidity, and Bluetooth module; (b) real-time clock, SD card reader, and LCD; (c) current regulator and batteries.

The data flow is transmitted in real time through the integrated BlueTooth ${ }^{\mathrm{TM}}$ module HC-06 to any device capable of receiving within a radius of $10 \mathrm{~m}$ or more (the exact maximum distance was not tested, as it varies due to environmental conditions). An algorithm in Arduino programming language $(\mathrm{C} / \mathrm{C}++$ based) was developed and implemented for the sensor control.

Multiple sensors in the sensor system allow the results between sensors to be checked in real time and reject incorrect readings or estimate the mean values between several sensors and apply sensor fusion and machine learning algorithms, thus avoiding incorrect measurements with cost-effective electronic components. One data line consists of the read resistances (analogue signal) from the MQ2, MQ4, and MQ135 sensors, and the relative humidity and the temperature (digital signal) from the DHT22 sensor with a time stamp calculated by the RTC module. The data string is saved to the SD card (4 Gb, speed class 10 used) using the RTC module in CSV format by creating a new file after starting the device or adding a new line at the end of the opened digital file. The HC-06 module pairs 
with the desired Android device and receives a data packet when streaming at a speed of $115,200 \mathrm{kbps}$ to a mobile device (a Samsung S6 Edge + was used) running the Android operating system via a Bluetooth scanning application (the free application ArduTooth was used). During the experimental studies, the data were also transferred to the controller Spectra Precision MobileMapper 50 of the Spectra Precision geodetic GPNS receiver SP60 (Figure 4).

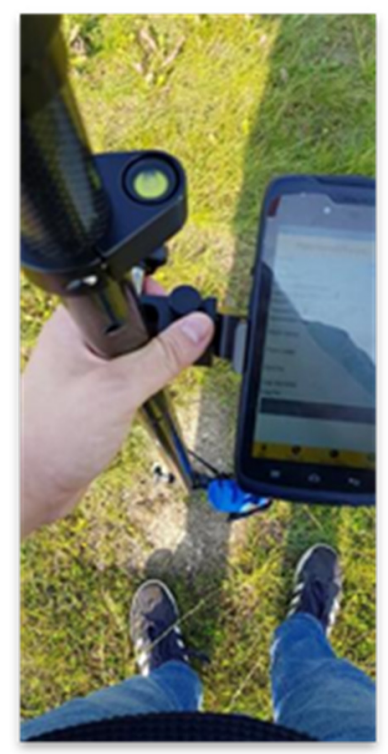

Figure 4. Static measurement with a sensor: geodetic pole with global navigation satellite system (GNSS) receiver, the gas measuring device is attached near the ground.

Global geographic coordinates recorded by a professional geodetic (leisure equipment or consumer grade if necessary) GNSS device moving at the landfill site, in characteristic places or at a given interval (time or distance) are recalculated in the state coordinate system and the height of each point. The sensor measures, records, and transmits readings continuously at a frequency of $1 \mathrm{~Hz}$. The GPNS receiver operates in RTK mode, is configured to, and receives corrections via GSM connection from the network of permanent continuous stations of the control (LitPOS) information system, thus obtaining an average error of no more than $2 \mathrm{~cm}$ for the horizontal position. Pre-processing is not required after measurements with the device are made in the area, but in the event of technical obstacles, some data rows may be damaged or recorded incompletely. Such rows need to be taken care of by deleting or manually filling in most common or average values to incomplete rows by using programming tools or Microsoft Excel.

The device was calibrated before using in field measurements.

\subsubsection{Device Calibration}

The calibration of the gas sensor prototype was performed in the environmental laboratory of Luleå University of Technology in Sweden. A sealed diffusion-proof gas collection bag was used for the tests. Air was removed from the bag before the test by an air compressor. After the electronic components had warmed up (stable readings had been reached), a known amount of gas was injected into the bag through a valve system with a glass syringe (Figure 5). A high purity gas for laboratory instrument calibration from AGA Gas $\mathrm{AB}$ was used for the sensor calibration.

After extracting the gas with an air compressor, known amounts of known gases $\left(\mathrm{CH}_{4}, \mathrm{CO}_{2}\right)$ were injected using a glass syringe. Resistance values measured with the electronic sensor were converted into the gas concentration expressed in $\mathrm{ppm}$. After the first attempt at calibrating the sensors, the device was improved by redesigning the connections, separating the sensor block, and repeating the measurements. The obtained data were used 
to generate a calibration curve. Additionally, several tests were performed to determine the sensitivity of the sensors and to define the measurement limits and conditions.

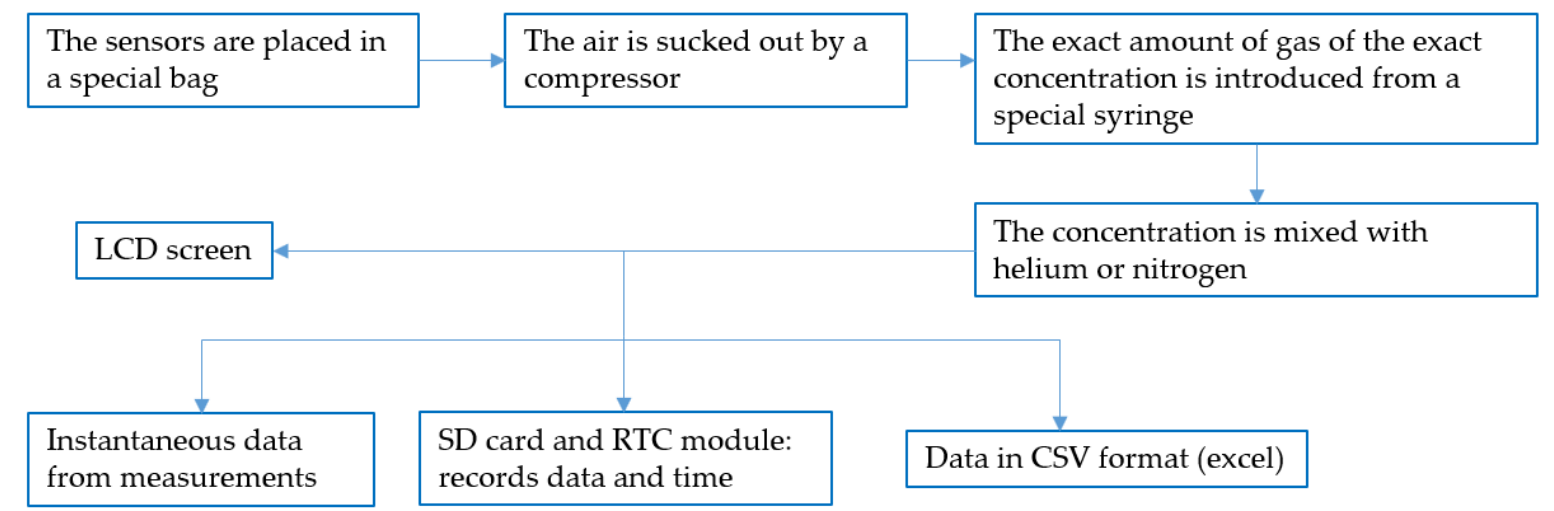

Figure 5. Explanatory diagram for obtaining calibration data in the laboratory.

Twelve-point tables with increasing known $\mathrm{CH}_{4}$ concentrations and other gases were compiled for each sensor. The values were in a range of $100 \mathrm{k} \mathrm{ppm}$ up to $500 \mathrm{k} \mathrm{ppm}$. Each gas concentration was compared to the decimal analogue value obtained over an average of several $300 \mathrm{~s}$ readings. Three test sessions were performed at different concentrations of $\mathrm{CH}_{4}$ and $\mathrm{He}$ as the background gas.

The values of each sensor were compared with the precisely known amount of gas through the linear regression equation for the calibration of each sensor. To derive the equation, a linear correlation between the parameters was calculated. The straight-line approximation of the true relationship was made. An important objective of regression analysis is to estimate the unknown parameters in the regression model; this process is also called fitting the model to the data $[18,19]$

The purpose of OLS is to determine estimates of regression parameters that minimise the sum of the squares of the values of the variable dependent on the actual $\left(y_{i}\right)$ and calculated $\left(\hat{y}_{i}\right)$ dependences of the selected regression equation. The method of ordinary least squares mathematically is written as follows:

$$
\sum\left(y_{i}-\hat{y}_{i}\right)^{2}=\sum e_{i}^{2} \rightarrow \min
$$

where $y_{i}$ is the actual value, $\hat{y}_{i}$ is the calculated value and $e_{i}$ is residual of each data point.

Using the statistics theory $[18,19]$, the correlation coefficients and the coefficient of determination were calculated, and the analogue values of the decimal system of the sensors and the known concentrations were related.

During testing, calibration, and experiments, the sensor readings and transmissions of the measurement data occurred once a second. After device calibration, an equation for each sensor was obtained; the variance of sample values was calculated, and goodness of fit was expressed by the coefficient of determination.

Using a factory datasheet, another slope was made from the table of points represented in a figure with logarithmic base. The ordinate was the resistance ratio of the sensor $\left(R_{s} / R_{o}\right)$, and the abscissa was the concentration of gases. $R_{S}$ represented the resistance in a target gas with different concentrations, $R_{o}$ indicated the resistance of the sensor in clean air [20]. Eighteen data points were extracted using the graphing software called "GetData Graph Digitizer", by extracting values from the intersections of sloped typical sensitivity curve lines and minor axis [21]. Then, the equation used for the calibration of concentrations from $200 \mathrm{ppm}$ to $5000 \mathrm{ppm}$ was derived. To obtain the $R_{s} / R_{o}$ ratio, an equation was used to convert analogue values to digital ones of the microcontroller to $R_{o}$ in clean air, and later, analogue to digital values were recalculated again for each second of measurements in field and divided by $R o$ to obtain $R_{S} / R_{o}$ ratio of the landfill site measurements. Then, inverses 
of laboratory and factory calibration equations were used again. Using the equations, the values measured at the landfill site were transformed into amounts of methane at a certain location and time.

\subsubsection{Measurement Processes in the Area of Interest}

The main module of the sensor system consisted of an analogue of the open platform microcontroller Arduino Uno with a package of six AA batteries and a compatible cable connector attached to a metal plate using a holder for the GNSS receiver rod, which was fixed $20 \mathrm{~cm}$ above the ground (Figure 6).

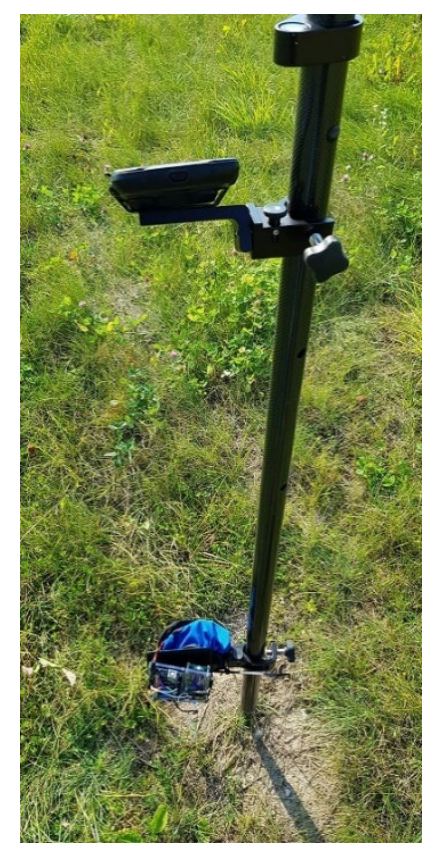

Figure 6. Device ready for measurements right above the ground.

Measurements were started by initialising each sensor. The gas sensors started immediately $(<1 \mathrm{~s})$, but it took time before the readings stabilised. The time duration depended on how frequently the device was used and on the temperature of each gas sensor. If the device had been switched on during the last couple of hours, it only took around $30 \mathrm{~s}$ for the readings to become stable. Otherwise, if the device was kept in warm, it would take some minutes, if used within a month. The device was restarted when stable readings were achieved.

Firstly, $R_{o}$ values were derived from at least a $30 \mathrm{~s}$ average of readings in clean air (clear of gases to be detected). Then, the readings were recalculated based on the calibration equation and $R_{o}$ for particular air conditions (temperature, humidity, pressure) and voltages, which depended on the sum of all hardware components (inner resistance) and battery charge level. Then, the real-time resistances were recalculated to quantities of the amount of $\mathrm{CH}_{4}$ gas in ppm.

For sensor measurements to be more accurate, the temperature should be close to that previously recommended during the calibration and in the factory specification (approximately $22{ }^{\circ} \mathrm{C}$ ); the wind should not be strong or there should be a constant internal flow. A strong change in humidity should be avoided if the change is not compensated by a real-time algorithm. The sensors can be upgraded to newer ones or be constructed with better characteristics, in most cases with little or no change to the algorithm code and circuit, and some sensors can be sold pre-calibrated at the factory. 


\section{Experimental Results and Analysis}

This subsection presents the measurement results obtained with the developed sensor array. Firstly, the system calibration results to determine the correlation between voltage values and gas concentration are provided, alongside a concise description of the experimental data with methane gas measurements at the landfill site.

An equation was derived for Rs/Ro ratio to be expressed as $\mathrm{CH}_{4}$ concentration ppm from the known characteristics of hardware and guidelines according to the manufacturer specifications:

$$
R_{S} / R_{\text {oppm }}=\left(\left(V /\left(V / \mathrm{ADC}_{\text {scale }} \cdot \mathrm{ADC}_{\mathrm{val}}\right)\right)-1\right) \cdot R_{L} / R_{\text {clean }}
$$

where $\mathrm{V}$-voltage of power supply of sensor (here $5 \mathrm{~V}$ ), $\mathrm{ADC}_{\text {scale }}$-maximum value of analogue to digital converter of microcontroller (here 1024), $\mathrm{ADC}_{\mathrm{val}}$-current reading of microcontroller, $R_{L}$-load resistance (here $500 \mathrm{ohm}$ ), $R_{\text {clean }}-R_{S} / R_{o}$ ratio in clean air (or when gas concentration we are calibrating is not present in sensors vicinity).

\subsection{Sensor System Calibration Results}

For each sensor, linear regression using the OLS method was fitted, and the main statistics (coefficient of determination, adjusted, $\mathrm{p}$ and $\mathrm{t}$ statistics) were calculated and provided. The Python 3 programming environment with matplotlib, statsmodels, and pandas libraries were used for calculations.

All results are shown in Figures 7-9. The vertical axis shows the ratio of sensor resistance while in contact with $\mathrm{CH}_{4}$ divided by resistance in so-called clean air (no $\mathrm{CH}_{4}$ or similar gases). The horizontal axis shows $\mathrm{CH}_{4}$ concentration in a thousand parts per million (in short $\mathrm{k} \mathrm{ppm}$ or $10^{3} \mathrm{ppm}$ ). Linear regression equations were obtained with a good fit, as the coefficients of determination $\mathrm{r}^{2}$ were ranging from 0.937 to 0.987 .

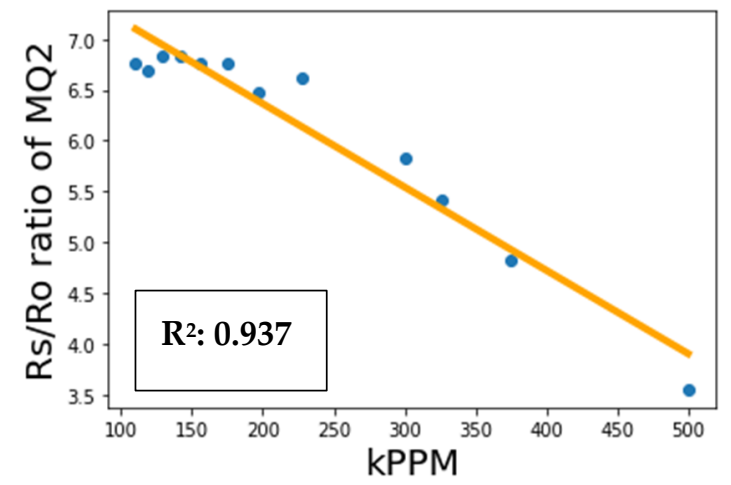

Figure 7. Calibration curve for MQ2 sensor integrated in a device.

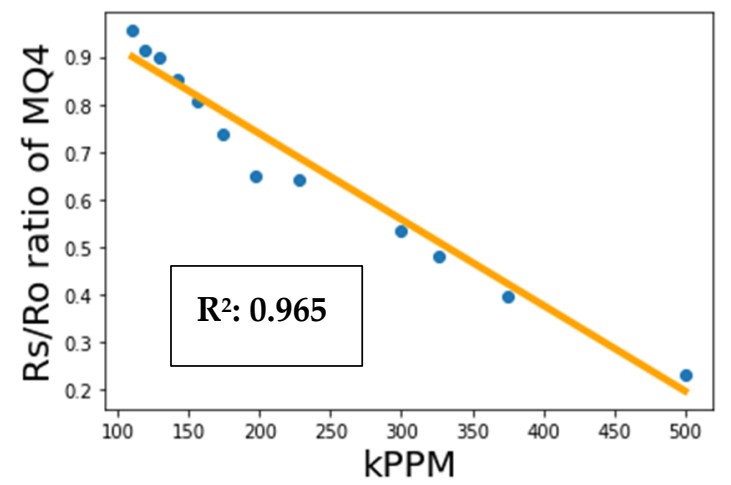

Figure 8. Calibration curve for MQ4 sensor integrated in a device. 


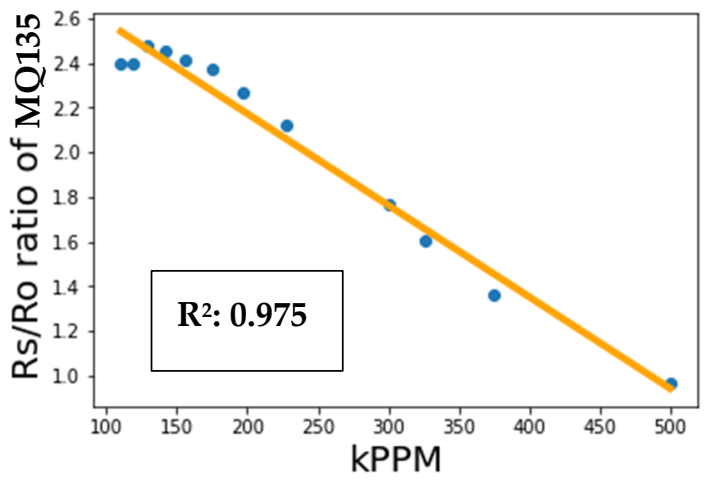

Figure 9. Calibration curve for MQ135 sensor integrated in a device.

Based on recent traditional landfill site monitoring reports in Lithuania, when results are reported, it is common to state that the correlation of calibration is considered reliable when $\mathrm{r}^{2}>0.8$.

According to the calibration curve (Figure 7), the equation is formed as:

$$
\hat{y}=-0.0082 \cdot x_{1}+8.0024
$$

for which $p=0.001(p<0.05)$, and the adjusted coefficient of determination $\mathrm{r}^{2}$ adj $=0.930$ (Table 1). The "statmodels" library was used to calibrate the MQ2 sensor, and Tables 1 and 2 show the results of the mathematical statistics that were created.

Table 1. OLS regression results (MQ2).

\begin{tabular}{cccc}
\hline Dep. Variable: & MQ2 & R-squared: & 0.937 \\
Model: & OLS & Adj. R-squared: & 0.930 \\
Method: & Least Squares & F-statistic: & 148.2 \\
No. Observations: & 12 & Prob (F-statistic): & $<0.001$ \\
Df. Residuals: & 10 & Log-Likelihood: & -0.34493 \\
Df. Model: & 1 & AIC: & 4.690 \\
Covariance Type: & nonrobust & BIC: & 5.660 \\
\hline
\end{tabular}

Table 2. OLS regression results (MQ2 continued).

\begin{tabular}{ccccccc}
\hline Value & Coef. & Std. err & $\mathbf{t}$ & $\boldsymbol{p}>\mathbf{[ t}]$ & {$[\mathbf{0 . 0 2 5}$} & $\mathbf{0 . 9 7 5}]$ \\
\hline Constant & 8.0024 & 0.174 & 45.896 & 0.000 & 7.614 & 8.391 \\
PPM & -0.0082 & 0.001 & -12.173 & 0.000 & -0.010 & -0.007 \\
\hline
\end{tabular}

The "statsmodels" library was used to calibrate the MQ4 sensor, and Tables 3 and 4 display the results of the created mathematical statistics, as shown in Figure 8.

Table 3. OLS regression results (MQ4).

\begin{tabular}{cccc}
\hline Dep. Variable: & MQ4 & R-squared: & 0.965 \\
Model: & OLS & Adj. R-squared: & 0.961 \\
Method: & Least Squares & F-statistic: & 273.9 \\
No. Observations: & 12 & Prob (F-statistic): & $<0.001$ \\
Df. Residuals: & 10 & Log-Likelihood: & 21.327 \\
Df. Model: & 1 & AIC: & -38.65 \\
Covariance Type: & nonrobust & BIC: & -37.68 \\
\hline
\end{tabular}


Table 4. OLS regression results (MQ4 continued).

\begin{tabular}{ccccccc}
\hline Value & Coef. & Std. err & $\mathbf{t}$ & $\boldsymbol{p}>\mathbf{t}]$ & {$[\mathbf{0 . 0 2 5}$} & $\mathbf{0 . 9 7 5 ]}$ \\
\hline Const & 1.0981 & 0.029 & 38.329 & 0.000 & 1.034 & 1.162 \\
PPM & -0.0018 & 0.000 & -16.551 & 0.000 & -0.002 & -0.002 \\
\hline
\end{tabular}

According to the calibration curve (Figure 8), the equation is formed as:

$$
\hat{\mathrm{y}}=-0.0018 \cdot \mathrm{x}_{1}+1.0981
$$

which is $p=0.001(p<0.05)$. The adjusted coefficient of determination $\mathrm{r}^{2}$ adj $=0.961$ (Table 3).

According to the calibration curve (Figure 9), the equation is formed as:

$$
\hat{y}=-0.0041 \cdot x_{1}+2.9936
$$

which is $p=0.001(p<0.05)$. Adjusted coefficient of determination $\mathrm{r}^{2}$ adj $=0.972$ (Table 5). Coefficients described in Table 6.

Table 5. OLS regression results (MQ135).

\begin{tabular}{cccc}
\hline Dep. Variable: & MQ135 & R-squared: & 0.975 \\
Model: & OLS & Adj. R-squared: & 0.972 \\
Method: & Least Squares & F-statistic: & 387.9 \\
No. Observations: & 12 & Prob (F-statistic): & $<0.001$ \\
Df. Residuals: & 10 & Log-Likelihood: & 13.802 \\
Df. Model: & 1 & AIC: & -23.60 \\
Covariance Type: & nonrobust & BIC: & -22.63 \\
\hline
\end{tabular}

Table 6. OLS regression results (MQ135 continued).

\begin{tabular}{ccccccc}
\hline Value & Coef. & Std. err & $\mathbf{t}$ & $p>[\mathbf{t}]$ & {$[\mathbf{0 . 0 2 5}$} & $\mathbf{0 . 9 7 5}]$ \\
\hline Const & 2.9936 & 0.054 & 55.813 & 0.000 & 2.874 & 3.113 \\
PPM & -0.0041 & 0.000 & -19.694 & 0.000 & -0.005 & -0.004 \\
\hline
\end{tabular}

The data fit description shows a confident correlation in high concentrations from roughly $100 \mathrm{k}$ to $500 \mathrm{k} \mathrm{ppm} \mathrm{CH}_{4}$, and an even better resolution could be achieved by calibrating for shorter ranges such as $250 \mathrm{k}-500 \mathrm{k} \mathrm{ppm}$ or fitting 2-degree polynomials, or in some cases, applying logarithmic scales for a wider range.

For smaller than previously described concentrations from $200 \mathrm{ppm}$ to $10 \mathrm{k} \mathrm{ppm}$, the manufacturer provided this data table (Table 7):

Table 7. Rs/Ro and concentration values of $\mathrm{CH}_{4}$ from the MQ4 sensor datasheet.

\begin{tabular}{cccccccccc}
\hline PPM & 200 & 300 & 400 & 500 & 600 & 700 & 800 & 900 & 1000 \\
Rs/Ro ratio & 1.752 & 1.518 & 1.369 & 1.264 & 1.186 & 1.122 & 1.070 & 1.028 & 0.988 \\
PPM & 2000 & 3000 & 4000 & 5000 & 6000 & 7000 & 8000 & 9000 & 10,000 \\
Rs/Ro ratio & 0.772 & 0.675 & 0.613 & 0.566 & 0.527 & 0.495 & 0.468 & 0.450 & 0.432 \\
\hline
\end{tabular}

From following data, the equation is derived as:

$$
\mathrm{y}=11.531 x^{-0.355}
$$

with $R^{2}=0.9998$. After tests in the field, the inverse of this equation was used. 


\subsection{Result of Measurement in the Landfill}

The sensor, tested under laboratory conditions, was used in the research object under the conditions of the Kariotiskes landfill. The gas concentration change measurement data are plotted on an absolute time scale and, if a professional geodetic GPS device is used, a thematic map of the landfill area, where the ordinates and abscissas of the measured points are related to the measured $\mathrm{CH}_{4}$ concentrations or $\mathrm{mV}$ values from each sensor, can be derived. The test was only conducted in parts of the landfill site where vegetation conditions were lower than in their surroundings.

Prior to the measurements, the sensor was initialised at the landfill site (central part). The measured gas emanated from the well by enclosing it in a bag and five regions were selected in the area where the previous plant NDVI index had values from 0.1-0.2 and may have contained vegetation experiencing water stress due to Land Field Gas exposure. Vegetation and cover observations results were generated using Trimble UX5 UAV data acquired in 2018. The NIR sensor (a Sony mirrorless NEX-5R camera) was used to capture two coloured bands and one NIR band. The same-day TIR images were generated from data acquired using the DJI Matrice 200 UAV in 2018. The images were acquired in areas found to have unusually low NDVI values to determine whether their temperatures differed from those of their surroundings (Figure 10) [22].

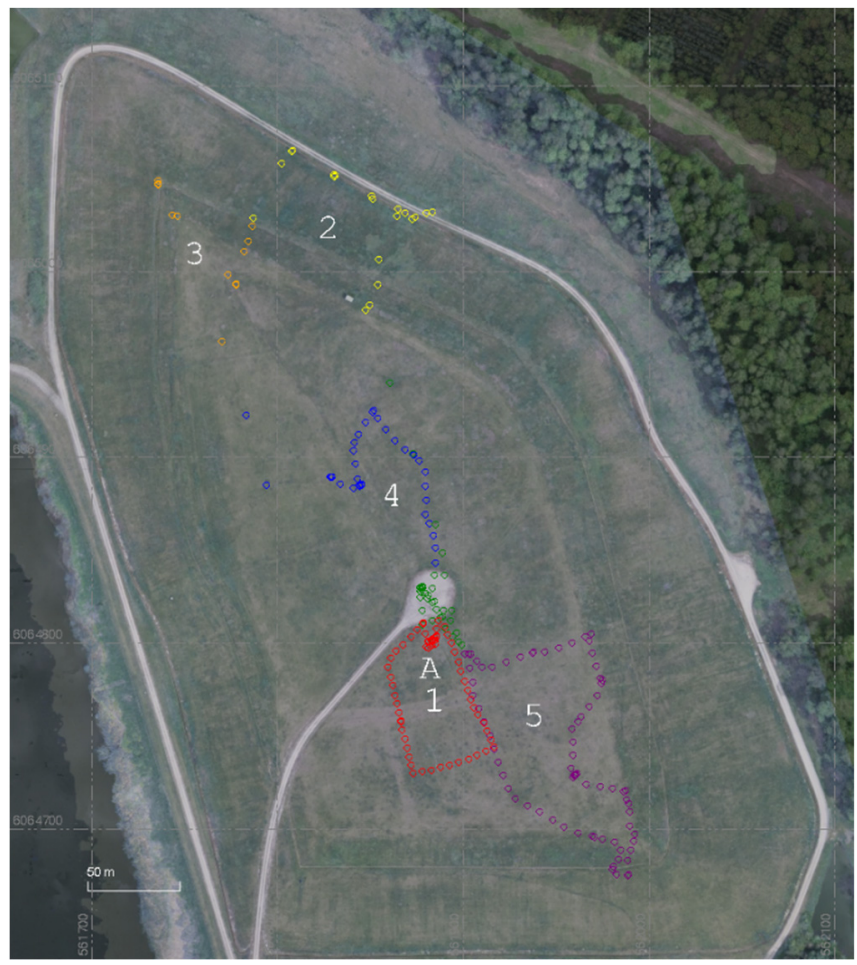

Figure 10. Graphical representation of points of interest and test session.

The first point was south of the central part near the gas collection well, the second in the centre of the north-eastern slope, the third in the northernmost part of the hump, the fourth in the northern part of the hub, and the fifth in the south-eastern part of the hump (Figure 10).

Figure 11 shows data collected during ca. after two hours of roving across the field and more than 5000 lines of data with sensor voltage values (results of 10-bit analogue to digital converter onboard of microcontroller) expressed as a function of time. 


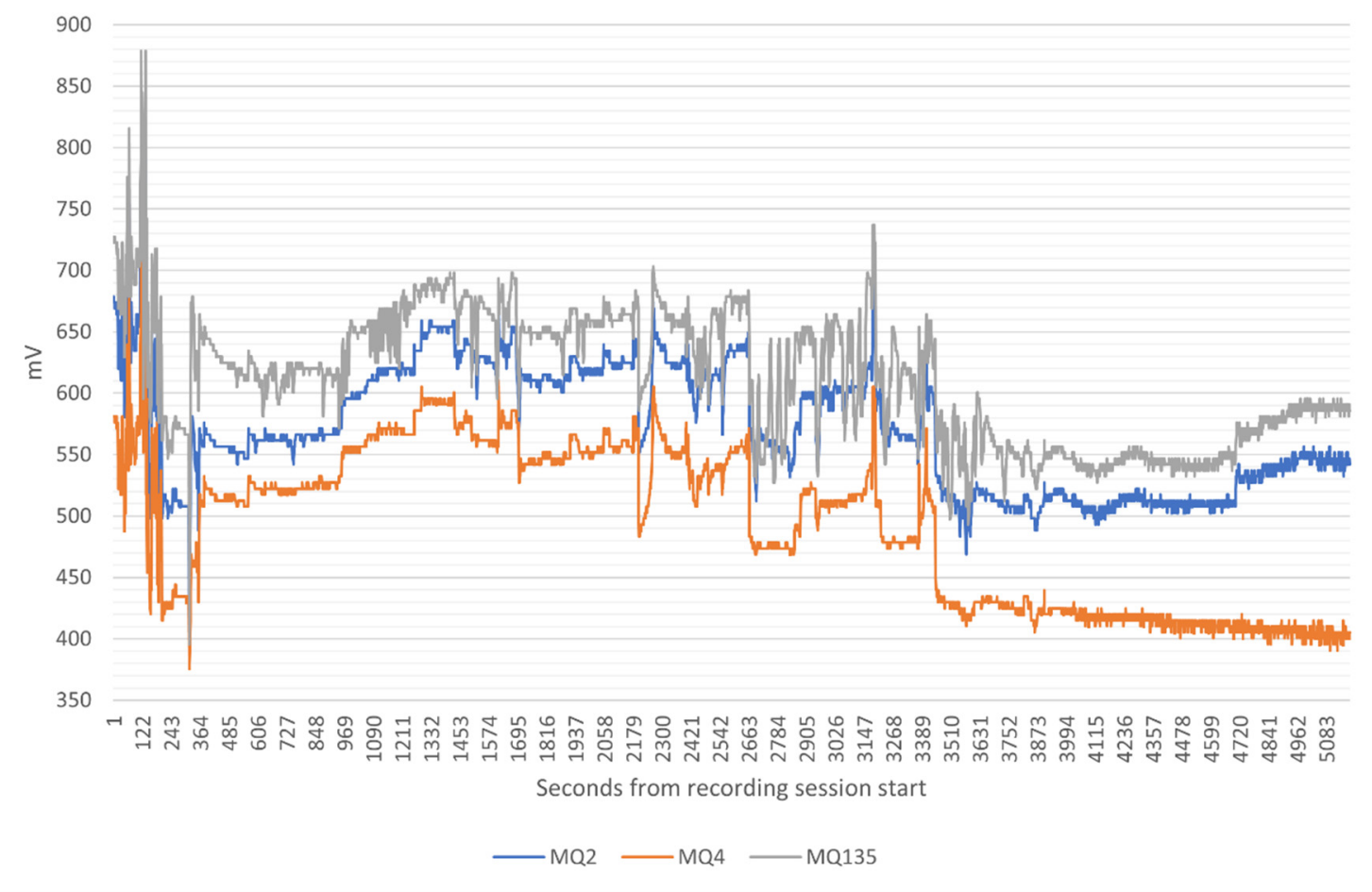

Figure 11. Graph showing the data of experimental studies conducted by the MQ2, MQ4, and MQ135 sensors in the Kariotiskes landfill site.

The data recorded by the MQ2 sensor showed a minimum value of $390 \mathrm{mV}$, a maximum value of $835 \mathrm{mV}$, an average value of $571 \mathrm{mV}$, and a standard deviation of $49 \mathrm{mV}$; the average of the $75 \%$ highest values was $615 \mathrm{mV}$. The data recorded by the sensor MQ4 showed a minimum value of $376 \mathrm{mV}$, with a mean value $493 \mathrm{mV}$, a standard deviation of $49 \mathrm{mV}$, and $75 \%$ of the highest values with a mean of $552 \mathrm{mV}$. The data recorded by the sensor MQ135 showed a minimum value of $396 \mathrm{mV}$, a maximum value of $879 \mathrm{mV}$, an average value of $616 \mathrm{mV}$, and a standard deviation of $52 \mathrm{mV}$; the average of the $75 \%$ highest values was $654 \mathrm{mV}$.

In summary, the minimum sensor values from $376 \mathrm{mV}$ to $879 \mathrm{mV}$ for all measurement data and the average values from 493 to $612 \mathrm{mV}$ were obtained. Although the absolute values did not coincide between the sensors, in most cases, the trends (increase or decrease) coincided.

The values detected with a specialised methane gas sensor were converted from millivolts to ppm and are plotted in Figure 12.

The measured values were generalised, interpolated and overlayed on an ortophotographic map, shown in Figure 13.

Previously mentioned areas or points of interest showed different values, but all were below the minimum detectable value of the specified gas sensor. 


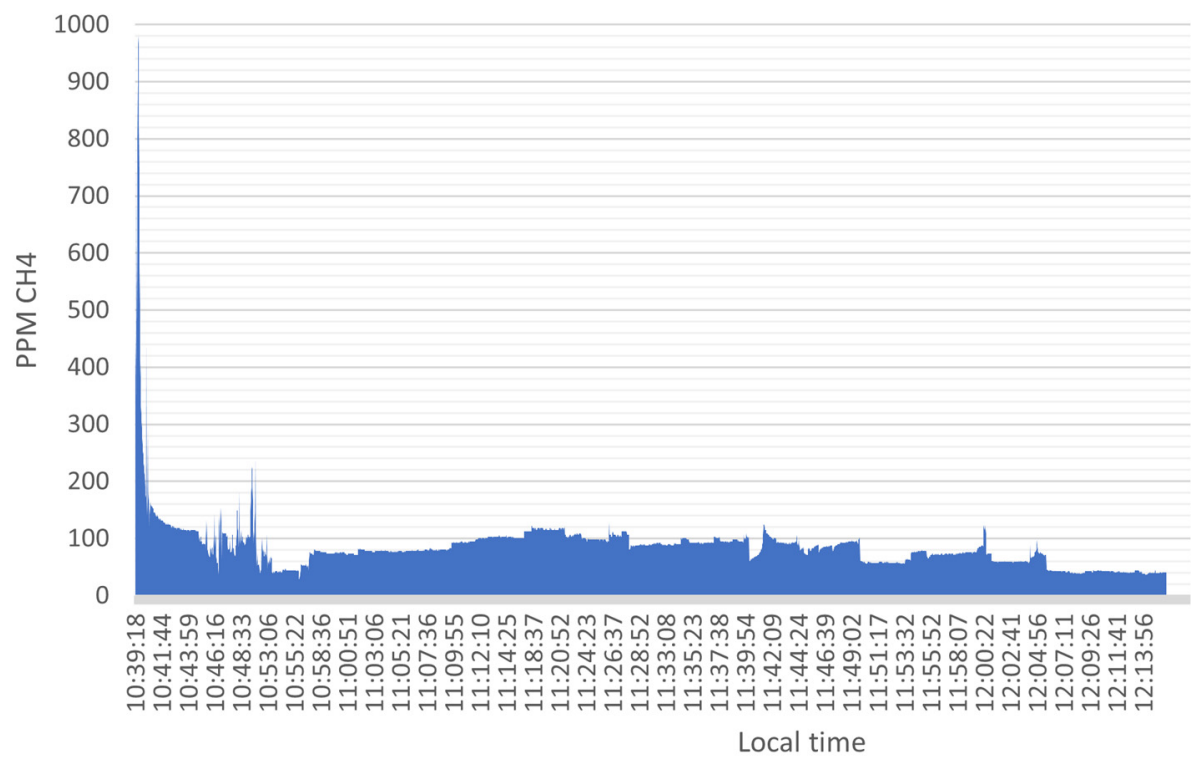

Figure 12. Gas sensor MQ4 data, ppm values as a function of time in Kariotiskes landfill site.

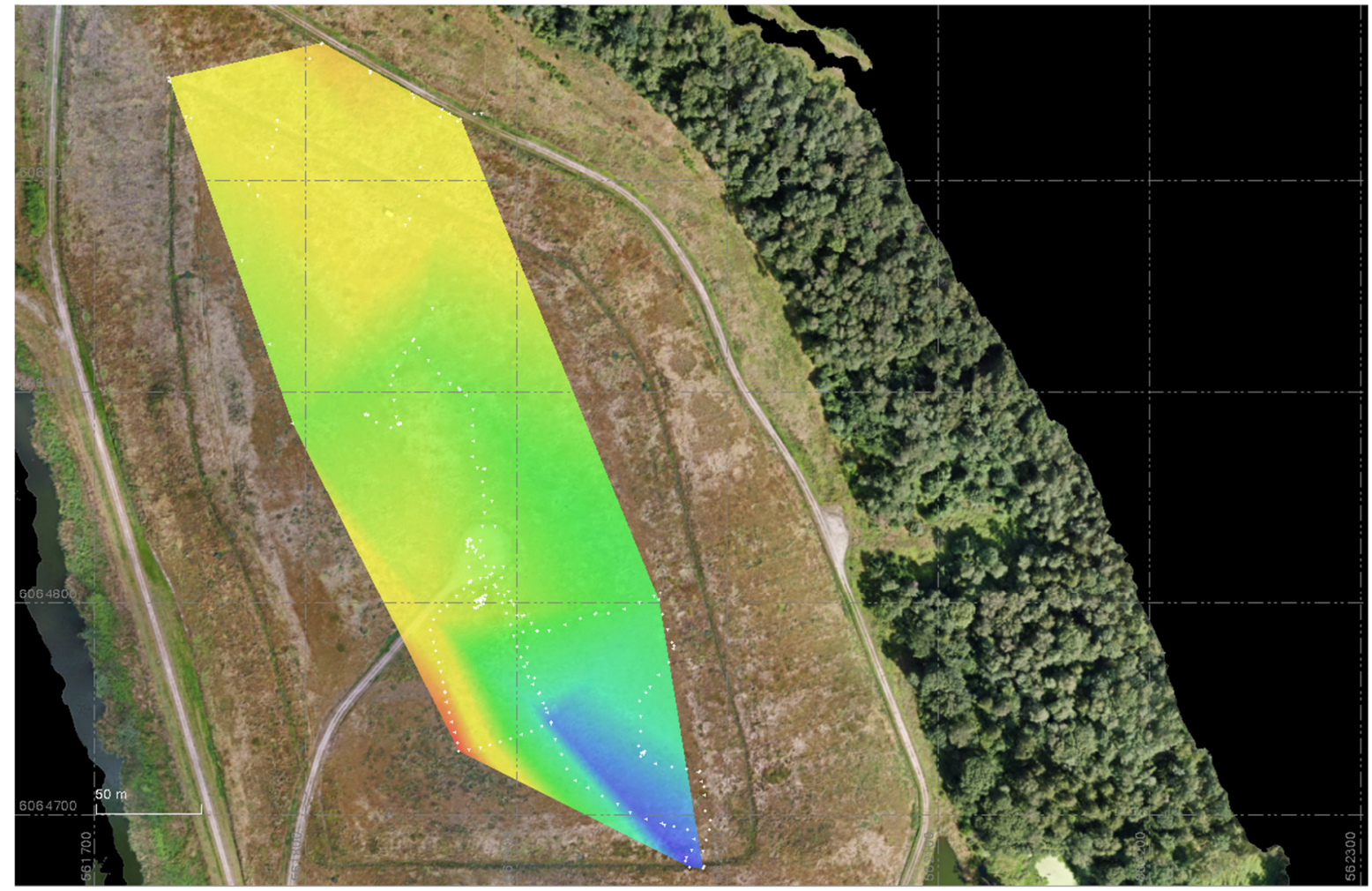

Figure 13. Gas sensor data of experimental studies conducted with the MQ4 sensor in the Kariotiskes landfill site.

\section{Discussion and Conclusions}

A prototype sensor was constructed in order to easily and quickly check landfill sites for $\mathrm{CH}_{4}$ gas emissions. The components and system design were aimed at creating a fast response device with roving capabilities to improve the process of gas monitoring and detection. Such a solution has a potential to replace the static flux chamber in certain situations, is economically more available than laser detection systems, and is better at the detailed detection of small emission sources than satellite images. There are other more 
accurate devices and technologies available, but they are high-cost and lack either the speed of detection or an ability to scan the whole area with a good resolution.

The calibration of the tested low-cost semiconductor gas sensors showed a good fit of the model to data, indicating that these sensors can be used beyond the household application and outside the limits specified in a datasheet. The calibration of the sensor array (for sensors MQ2, MQ4, and MQ135) from 100k ppm to 500k ppm of $\mathrm{CH}_{4}$ resulted in coefficients of determination $\mathrm{r}^{2}$ ranging from 0.94 to 0.99 ; these and other parameters indicate that formulas provided can be used for conversion from a resistance ratio to ppm of $\mathrm{CH}_{4}$ in similar conditions using this prototype. Although the risk of damaging the sensor was possible when dealing with such high concentrations, the performed tests indicated that the application of the sensor array was capable of showing gas leaks up to 500k ppm. Although in the studied landfill site, no gas leaks were found, which would indicate any sign of cracks with $\mathrm{CH}_{4}$ emissions through the landfill cover, the sensor array reacted to the gas flow from the gas collection well when in its vicinity. For concentrations from $200 \mathrm{ppm}$ to $10 \mathrm{k} \mathrm{ppm}$, data points from the factory datasheet graph were extracted and the logarithmic equation obtained with $\mathrm{r}^{2}=0.9998$. The sensor reacts proportionally with a similar curve through a long range of concentrations with a good fit to a statistical model. The main idea is not to find an exact amount of $\mathrm{CH}_{4}$, but to find the geographical direction in which the amount increases, while roving through the landfill site or checking points of interest and determining whether it is under influence of air contamination. Based on the results, it is shown that it is possible to use the prototype to check for leaks with $\mathrm{CH}_{4}$ emission.

Real-time measurements of the relative amounts of particular gases with specific contents, in this case applied in a landfill site for $\mathrm{CH}_{4}$ detection, can provide a rapid and roving tool to check any location or part of territory almost instantly, as opposed to collecting air samples statically in predefined locations or with far more expensive equipment. Economical and accessible parts available around the world could provide a possibility for many closed landfill site engineers to try this sensor setup to scan large areas for cracks with $\mathrm{CH}_{4}$ leakage in the case of some visual indications or monitoring with UAVs. When small to negligible concentrations are expected, the factory datasheet with the calibration curve can be used. For concentrations above 100k, a specific calibration of the sensor is recommended.

Author Contributions: Conceptualization, I.D. and J.K.; methodology, I.D., J.K.; software, I.D., I.S.; validation, I.D., J.K., J.S.V., I.S.; formal analysis, I.D.; investigation, I.D.; resources, J.S.V.; data curation, I.D., I.S.; writing—original draft preparation, J.S.V., I.D.; writing—review and editing, J.K.; visualization, I.D.; supervision, J.S.V.; project administration, J.S.V.; funding acquisition, J.S.V. All authors have read and agreed to the published version of the manuscript.

Funding: This research received no external funding.

Data Availability Statement: The data presented in this study are available on request from the corresponding author.

Conflicts of Interest: The authors declare no conflict of interest.

\section{References}

1. $\quad$ Allen, M.R.; Babiker, M.; Chen, Y.; Coninck, H.D.; Connors, S.; Diemen, R.V.; Dube, O.P.; Ebi, K.L.; Engelbrecht, F.; Ferrat, M.; et al. Summary for Policymakers. In Global Warming of 1.5: An IPCC Special Report on the Impacts of Global Warming of 1.5 \C above Pre-Industrial Levels and Related Global Greenhouse Gas Emission Pathways, in the Context of Strengthening the Global Response to the Threat of Climate Change, Sustainable Development, and Efforts to Eradicate Poverty IPCC; World Meteorological Organization: Geneva, Switzerland, 2018; pp. 1-24. Available online: https://www.ipcc.ch/sr15/chapter/spm/ (accessed on 13 May 2021).

2. Rahmstorf, S. A semi-empirical approach to projecting future sea-level rise. Science 2007, 315, 368-370. [CrossRef]

3. Dräger X-am®7000. Available online: https://www.draeger.com/Products/Content/x-am-7000-pi-9044772-en-gb.pdf (accessed on 4 May 2021).

4. Marcinonis, A. Babẻnu Buitiniu Atlieku Sąvartyno Teritorijos Aplinkos Monitoringas. Available online: https://www.kaunoratc. lt/wp-content/uploads/2019/12/Babenai_2010-2013ataskaita_internetui.pdf (accessed on 4 May 2021). 
5. Rolston, D.E. Gases Flux. Methods of Soil Analysis. Part 1. Physical and Mineralogical Methods; SSSA Book Ser. 5; SSSA: Madison, WI, USA, 1986; pp. 1103-1119. [CrossRef]

6. Lindau, C.W.; DeLaune, R.D. Dinitrogen and nitrous oxide emission and entrapment in Spartina alterniflora saltmarsh soils following addition of N-15 labelled ammonium and nitrate. Estuar. Coast. Shelf Sci. 1991, 32, 161-173. [CrossRef]

7. Yu, K.; Hiscox, A.; DeLaune, R.D. Greenhouse Gas Emission by Static Chamber and Eddy Flux Methods. SSSA Book 2013, 10. Available online: http:/ / faculty.troy.edu/kyu/2013-methods-wetlands-22.pdf (accessed on 4 May 2021).

8. Yang, S.; Liu, Y.; Wu, N.; Zhang, Y.; Svoronos, S.; Pullammanappallil, P. Low-cost, Arduino-based, portable device for measurement of methane composition in biogas. Renew. Energy 2019, 138, 224-229. [CrossRef]

9. Bennetts, V.M.H.; Lilienthal, A.J.; Khaliq, A.A.; Sese, V.P.; Trincavelli, M. Towards real-world gas distribution mapping and leak localization using a mobile robot with $3 \mathrm{~d}$ and remote gas sensing capabilities. In Proceedings of the 2013 International Conference on Robotics and Automation, Karlsruhe, Germany, 6-10 May 2013. [CrossRef]

10. Innocenti, F.; Robinson, R.; Gardiner, T.; Finlayson, A.; Connor, A. Differential absorption Lidar (DIAL) measurements of landfill methane emissions. Remote Sens. 2017, 9, 953. [CrossRef]

11. Tanda, G.; Migliazzi, M.; Chiarabini, V.; Cinquetti, P. Application of close-range aerial infrared thermography to detect landfill gas emissions: A case study. J. Phys. 2017, 796, 012016. [CrossRef]

12. Adão, T.; Hruška, J.; Pádua, L.; Bessa, J.; Peres, E.; Morais, R.; Sousa, J.; Adão, T.; Hruška, J.; Pádua, L.; et al. Hyperspectral imaging: A review on UAV-based sensors, data processing and applications for agriculture and forestry. Remote Sens. 2017, 9, 1110. [CrossRef]

13. Abrams, M.J.; Hook, S.J. NASA's hyperspectral infrared imager (HyspIRI). In Thermal Infrared Remote Sensing; Kuenzer, C., Dech, S., Eds.; Springer: Dordrecht, The Netherlands, 2013; Volume 17. [CrossRef]

14. Hochberg, E.J.; Roberts, D.A.; Dennison, P.E.; Hulley, G.C. Special issue on the Hyperspectral Infrared Imager (HyspIRI): Emerging science in terrestrial and aquatic ecology, radiation balance and hazards. Remote Sens. Environ. 2015, 167, 1-5. [CrossRef]

15. Hulley, G.C.; Duren, R.M.; Hopkins, F.M.; Hook, S.J.; Johnson, W.R.; Eng, B.T.; Mihaly, J.M.; Chazanoff, V.M.; Staniszewski, S.L.; Aubrey, A.D. High spatial resolution imaging of methane and other trace gases with the airborne Hyperspectral Thermal Emission Spectrometer (HyTES). Atmos. Meas. Tech. 2016, 9, 2393. [CrossRef]

16. Bhargava, A.K. Atmospheric Monitoring Using Arduino Boards and Low Cost Sensors. International Conference on New Horizons in Science and Management and Humanities 2021 (NHSEMH-18). Available online: http:/ / data.conferenceworld.in/ IIMT_NHSEMH/1.pdf (accessed on 4 May 2021).

17. Schuyler, T.J.; Guzman, M.I. Unmanned Aerial Systems for Monitoring Trace Tropospheric Gases. J. Atmos. 2017, 8, 206. [CrossRef]

18. Thompson, B. Canonical Correlation Analysis. Sage Publications 1984, USA. Available online: https://books.google.lt/books? $\mathrm{hl}=\mathrm{lt} \& \mathrm{lr}=\& \mathrm{id}=\mathrm{Dk} 0$ XINOvsw8C\&oi=fnd\&pg=IA1\&dq=correlation+analysis\&ots=3buz-30Wrd\&sig=kR5N5rJw4knQipZWU3 8d1cOt5vQ\&redir_esc=y\#v=onepage\&q=correlation\%20analysis\&f=false (accessed on 4 May 2021).

19. Montgomery, D.C.; Peck, E.A.; Vining, G.G. Introduction to Linear Regression Analysis, 2nd ed.; Wiley: Hoboken, NJ, USA, 1992.

20. Technical data MQ-4 Gas Sensor-SparkFun Electronics. Available online: https://www.sparkfun.com/datasheets/Sensors/ Biometric/MQ-4.pdf (accessed on 4 May 2021).

21. Zein, H.; Tran, V.L.H.; Abdelmotaleb, G.A.; Mohammed, A.T.; Ahmed, A.; Iraqi, A.; Nguyen, H. How to Extract Data from Graphs Using Plot Digitizer or Get Data Graph Digitizer. Technical Report 2015. Available online: https://www.academia.edu/32440572 /How_to_Extract_Data_from_Graphs_using_Plot_Digitizer_or_Getdata_Graph_Digitizer (accessed on 4 May 2021).

22. Daugèla, I.; Suziedelyte Visockiene, J.; Kumpiene, J. Detection and analysis of methane emissions from a landfill using unmanned aerial drone systems and semiconductor sensors. Detritus-Multidiscip. J. Waste Resour. Residues 2020, 10, 127-138. [CrossRef] 